\title{
Mortars prepared with mechanochemical treated asbestos-containing waste
}

\author{
Alexander Mezhov ${ }^{*}, 1$,Ekaterina Shokodko $^{2}$, and Maria Kaddo $^{2}$ \\ ${ }^{1}$ Technion - Israel Institute of Technology, 3200003, Haifa, Israel \\ ${ }^{2}$ Moscow State University of Civil Engineering, Yaroslavskoe shosse, 26, Moscow, 129337, Russia
}

\begin{abstract}
The paper presents the results of recycling of asbestoscontaining waste (ACW). It is shown that hydraulic activity of ACW is increased using mechanochemical treatment in the vibratory ball mill in presence of anionic surfactant. Experimental results show that substitution of $10 \%$ w.t. of cement on activated asbestos-containing waste leads to increasing of the compressive strength to $20 \%$. Finally, the effect of the activated ACW on the hardening kinetics of mortars is examined.
\end{abstract}

\section{Introduction}

Asbestos cement materials have a doubtful reputation all around the world. Even countries with a long history of production and successful use have a ban on all asbestos materials [1]. However, regardless to the country the problem of efficient recycling of asbestoscontaining waste (ACW) is still exist.

Asbestos is a name of the group of six fibrous minerals: serpentine (chrysotile) type and amphibole type (crocidolite, amosite, anthophyllite, tremolite and actinolite). The name asbestos is more a commercial definition than a mineralogical specification [2]. Chrysotile and amphibole types of asbestos have different chemical composition and properties. The curretn research deals with chrysotile-asbestos only, which is the most popular type of asbestos [3] and has being used at production of cement-based materials. It is also known that not all types of asbestos are equally hazardous, according to the "amphibole hypothesis" [4], [5]. This hypothesis is based on the series of experiments showing that lung diseases are related with amphibole type of asbestos only. Nevertheless, all the asbestos minerals and asbestos containing materials are banned in $28 \%$ of countries in the world and in $72 \%$ of them only amphibole asbestos are prohibited. However it is possible to use chrysotile with a proper safety control and technology [6], [7].

After years of maintenance of asbestos cement materials, they have to be recycled. The easiest but not the cheapest way is to put them into special disposal sites [8], [9].

ACW contains about $80 \ldots 85$ wt. $\%$ of cement and $15 \ldots 20$ wt. $\%$ of asbestos fibers. Given a major amount of cement in asbestos cement materials, it is possible to suggest that ACW contains some amount of non-hydrated minerals, and therefore has potential

\footnotetext{
Corresponding author: alexander.m@technion.ac.il
} 
hydraulic activity. Generally, all types of ACW recycling technologies could be written as follow: thermal treatment; mechanical treatment; combined methods.

Thermal treatment of ACW has been used for a long time. Conventional process requires the temperature more than $1000{ }^{\circ} \mathrm{C}$ for total decomposition of asbestos fibers into non-hazardous material. The products of thermal treatment of ACW are being applied for preparation of traditional ceramics [10], shrinkage reducing raw material for clinker bricks [11] or geopolymers [12]. It is also known that inertisation of asbestos can be reached by means of microwave thermal treatment [13]. The products of microwave thermal treatment are also used for preparation the ceramic materials.

It is reported that chrysotile asbestos could be transformed into non-hazardous material such as forsterite by means of relatively low temperatures less than $700{ }^{\circ} \mathrm{C}$ and pressure less than 8.0 MPa [14].

There are just a few examples how to use thermal treatment of ACW to produce magnesium phosphate cement [15] and calcium sulfoaluminate clinker [16]. It is also known that this method is suitable for preparation of supplementary materials for concrete [17]. Substitution of $5 ; 10 ; 15 ; 20$ wt.\% of cement for products of thermal treatment of ACW reduces the compressive strength after 28 days to $6 ; 9 ; 15 ; 20 \%$ respectively. But after 90 days of curing the compressive strength of all the samples is nearly to reference sample.

It is reported that $\mathrm{ACW}$ after thermal treatment at the temperature $600 \ldots 700{ }^{\circ} \mathrm{C}$ gains hydraulic activity. It is possible to prepare the binder consisting $40 \ldots 50 \%$ w.t. of ACW after thermal treatment, $50 \ldots 60 \%$ w.t. of slag and $5 \%$ w.t. of gypsum. Compressive strength of this binder is $\approx 20 \ldots 25 \mathrm{MPa}$ after 28 days of hardening in water [18].

Another way to recycle ACW is to use mechanical or mechanochemical treatment. This kind of treatment is widely used in waste management [19]. During this process powder allows to obtain chemically active solid materials [20]. At the same time mechanochemical treatment have been used many times for ACW recycling. It is reported that after mechanochemical treatment by means of ring mill with rotating speed of $250 \mathrm{rpm}$, the asbestos was strongly transformed and even disappeared. Moreover the mechanochemical treatment of amphibole asbestos requires more time than chrysotile [21]. After mechanochemical treatment ACW obtains pozzolanic activity [8]. Milled powder that was received after milling was used for preparation of mortars with hydraulic lime that have a relatively low compressive strength.

Asbestos-containing natural materials, such as serpentine were treated by means of high energy milling in disc mill and planetary ball mill. By means of high energy milling in water solution, material tends to lose crystallinity. It is shown that the ratio between grinding mass and charge mass has a significant influence on this process [22].

There are a few mechanical methods of recycling ACW without high energy milling, but also without deconstruction of asbestos fibers. ACW is milled to specific surface 200 $\mathrm{m}^{2} / \mathrm{kg}$ then mixed with cement $15 \ldots 20 \mathrm{wt} . \%$ and water $10 \ldots 12 \mathrm{wt} . \%$. From this mixture, the tiles with the size $150 \times 150 \times 8 \mathrm{~mm}$ are casted with subsequent treatment under the pressure of 1.5 ..2.5 $\mathrm{MPa}$, temperature $70{ }^{\circ} \mathrm{C}$ and humidity $90 \%$ for 8 hours. These tiles have a compressive strength $\approx 10 \mathrm{MPa}$ and water absorption $<22 \%$ [23]. It is reported that ACW has been used for production of porous aggregates [24] for lightweight concrete and secondary coarse and fine aggregates for the ordinary concrete [25]. These methods require a relatively low energy amount; however, it does not lead to the transformation of asbestos structure.

The general approach described in this paper is to activate ACW by means of mechanochemical treatment. The main difference between all abovementioned methods is introduction of the surfactant during the milling process. This method is described in several sources and has been used for the preparation of the so-called "Low Water Demand 
Binder (LWDB)" [26], [27] - mechanochemical treatment of cement in presence of anionic surfactant - Polynaphthalene Sulfonate (PNS). This technique allows to obtain concretes with low cement content and high mechanical properties. It is also possible to reduce the $\mathrm{CO}_{2}$ emission and extend shelf life without losing activity of binder.

There are several reasons why ACW could be sufficiently recycled into cement mortars: even old concrete consists the non-hydrated minerals and ACW contains about $80 \mathrm{wt} \%$ of cement instead of $15 \ldots 20 \mathrm{wt} . \%$ in conventional concrete; ACW after treatment gains pozzolanic activity [8], chrysotile asbestos has a positive influence on hydration kinetics of cement and it is shown that chrysotile fibers adsorb ions of $\mathrm{Ca}^{2+}$ from the cement pore solution [28] .

The current paper presents experimental results of mechanochemical treatment of ACW. Using the treated ACW the cement mortars were prepared. Different mixtures proportion were investigated: $5 ; 10 ; 15 ; 20$ wt. $\%$ of cement mass were substituted with activated ACW.

\section{Materials and methods}

The ACW samples are the cutting swarfs from the products. All the samples are taken from the chrysotile cement plant "Kombinat Kransny Stroitel" in Voskresensk, Moscow region. The samples were carefully transferred to the vibratory ball mill enclosed in a vial.

All the samples were investigated by Scanning Electron Microscopy (SEM), using JEOL JSM-U3 instrument. Chemical compositions of the samples were investigated by Energy-dispersive X-ray spectroscopy (EDS), using GETAC EDS instrument. XRD analysis was performed by Thermo ARL X'TRA High performance powder X-ray diffraction system. Particle size distribution was investigated by FRITSCH Laser particle sizer Analysette 22. Specific surface of the samples was measured in accordance to the conventional Blaine method.

Milling was performed in the vibratory ball mill; the grinding aids are stainless balls. The ratio between the grinding mass and the balls mass was 1:10. All the samples were divided into two parts, the first part was milled in the mill in dry conditions (ACW), the second was milled in the mill in dry conditions with surfactant (ACW+PNS). Plasticizers based on naphthalene sulfonate (PNS) was used as a surfactant. ACW was milled up to the specific surface $580 \mathrm{~m}^{2} / \mathrm{kg}$, as the reason will be described further. This is relevant for ACW and ACW interground with PNS. All mortars were prepared with cement to sand ratio 1:3 w.t. Cement was CEM I $42.5 \mathrm{~N}$. The chemical composition of cement is presented in Table 1.

Table 1. Chemical composition of cement (wt\%).

\begin{tabular}{|c|c|c|c|c|c|c|c|}
\hline $\mathrm{SiO}_{2}$ & $\mathrm{CaO}$ & $\mathrm{Al}_{2} \mathrm{O}_{3}$ & $\mathrm{Fe}_{2} \mathrm{O}_{3}$ & $\mathrm{MgO}$ & $\mathrm{SO}_{3}$ & $\mathrm{R}_{2} \mathrm{O}$ & LOI \\
\hline 21.6 & 66.7 & 5.34 & 4.27 & 0.7 & 0.15 & 0.6 & 0.64 \\
\hline
\end{tabular}

Sand was the quartz sand $0.16 \ldots 2.5 \mathrm{~mm}$. Mechanical properties were tested on prisms 4 x $4 \times 16 \mathrm{~cm}$ cured at $20 \pm 2{ }^{\circ} \mathrm{C}$ and $95 \% \mathrm{RH}$ for 24 hours, after this all the samples were demolded and immersed in water for 27 days. All the samples were prepared according to the Russian standard (GOST 310.4-81*. Cements. Methods of bending and compression strength determination) that requires to use water to cement ration 0.4 and the same workability measuring by the slump cone. According to the standard, in order to keep the same workability, water to cement ratio might be adjusted.

In order to compare the influence of different types of introduction of surfactant different mortars were prepared (Table 2). 
Table 2. Compositions of tested mortars.

\begin{tabular}{|c|c|c|c|c|c|c|}
\hline \# & Composition & Cement, $\mathrm{g}$ & Sand, $\mathrm{g}$ & Water, g & $\begin{array}{l}\text { Milled } \\
\text { ACW, g }\end{array}$ & PNS, g \\
\hline 1 & \multicolumn{6}{|c|}{ Reference } \\
\hline & Reference & 500 & 1500 & 215 & 0 & 0 \\
\hline 2 & \multicolumn{6}{|c|}{ Mortar is prepared with milled ACW, PNS is not introduced } \\
\hline & $10 \mathrm{ACW}$ & 450 & 1500 & 270 & 50 & 0 \\
\hline 3 & \multicolumn{6}{|c|}{ Mortar is prepared with milled ACW, PNS is introduced with water } \\
\hline & $10 \mathrm{ACW}+\mathrm{PNS}$ & 450 & 1500 & 259 & 50 & 3.5 \\
\hline 4 & \multicolumn{6}{|c|}{ Mortars are prepared with ACW milled with PNS } \\
\hline & $10(\mathrm{ACW}+\mathrm{PNS})$ & 450 & 1500 & 175 & 50 & 3.5 \\
\hline & $15(\mathrm{ACW}+\mathrm{PNS})$ & 425 & 1500 & 175 & 75 & 5.25 \\
\hline & $20(\mathrm{ACW}+\mathrm{PNS})$ & 400 & 1500 & 175 & 100 & 7.0 \\
\hline
\end{tabular}

Sample 1 is reference. Sample $2-10 \%$ wt. of cement is substituted to $10 \%$ wt. milled ACW, PNS is not introduced. Sample $3-10 \%$ wt. of cement is substituted to $10 \%$ wt. milled ACW, PNS is introduced chemically (dissolved in water). Samples: 4; 5; 6; 7 - 5; $10 ; 15 ; 20 \%$ wt. of cement is substituted to $10 ; 15 ; 20 \%$ wt. milled ACW, respectively, PNS is introduced mechanochemically (interground with ACW). The main difference between the samples 3 and 4 is introduction mode of superplasticizer.

\section{Results and discussion}

Milling separates the chrysotile fibers to a single bunch with subsequent reducing of the size of cement grains (Fig. 1). By means of XRD ACW was investigated before and after mechanochemical treatment in the presence of PNS (Fig. 2). ACW before the treatment contains non-hydrated calcium silicate $\left(\mathrm{C}_{3} \mathrm{~S}\right)$. XRD of ACW after treatment shows that the peak of chrysotile reduces that might indicate its amorphisation.

(a)

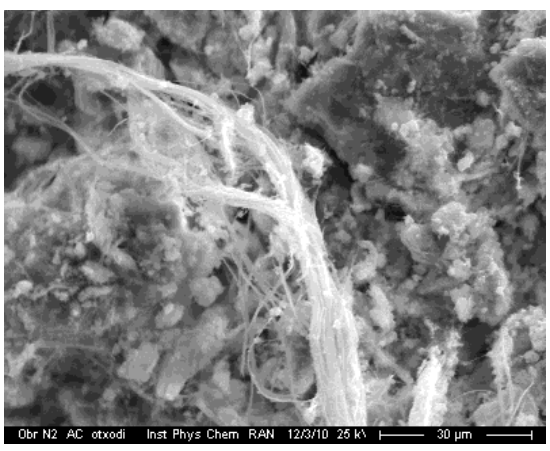

(b)

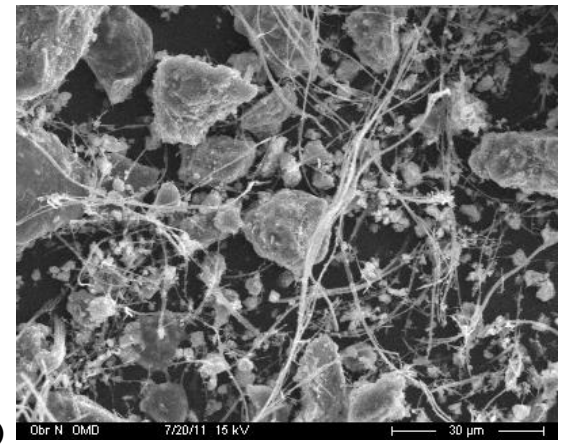

Fig. 1. SEM micrograph: (a) ACW before treatment; (b) ACW milled with PNS 


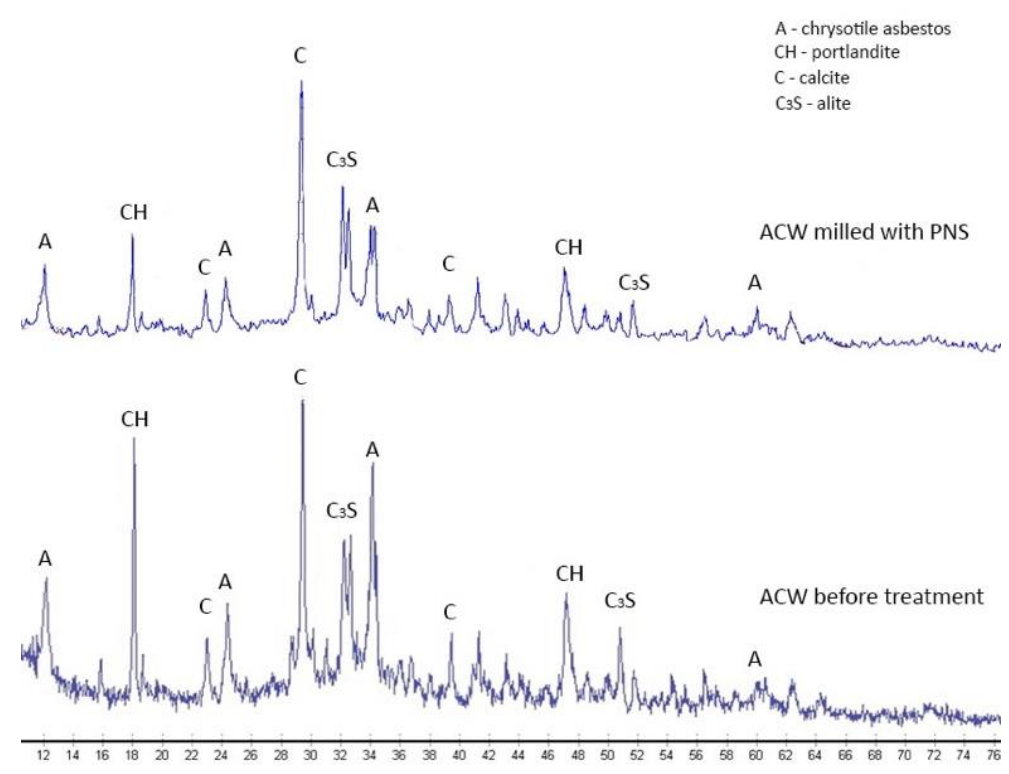

Fig. 2. XRD of ACW before treatment and ACW milled with PNS.

Table 3 presents chemical composition of ACW before and after treatment, amounts of components are very similar.

Table 3. Chemical composition of ACW (wt.\%).

\begin{tabular}{|l|c|c|c|c|c|c|c|}
\hline Measured item & $\mathrm{MgO}$ & $\mathrm{Al}_{2} \mathrm{O}_{3}$ & $\mathrm{SiO}_{2}$ & $\mathrm{SO}_{3}$ & $\mathrm{CaO}$ & $\mathrm{Fe}_{2} \mathrm{O}_{3}$ & Total \\
\hline ACW before treatment & 8.13 & 2.70 & 17.11 & 2.13 & 64.24 & 4.93 & 100 \\
\hline ACW milled with PNS & 8.90 & 2.07 & 17.44 & 3.87 & 63.53 & 4.00 & 100 \\
\hline
\end{tabular}

As is was mentioned before, mechanochemical treatment can increase hydraulic activity of ACW. It is known that milling reduces the particle sizes, while the new surfaces are formed. The obtained powder has a higher surface energy due to the mechanical impact.

In order to find an optimal regime of milling, an experimental dependence between the milling duration and specific surface was determined. Fig. 3. It shows how milling time influences the specific surface area of the reference powder (curve 2) and of that with PNS introduced into the mill (curve 1). The most efficient duration of milling is from 20 to 60 minutes. After this time, the process decreases, which means that particles are too small and they self-assemble back without separation, while the grinding aids are not able to split them anymore. Milling is accompanied by the two opposite processes - separation and aggregation of small particles. As a result of milling, cement grains are partially destroyed, and opposite charges appear on its surface. These charges force the small particles to link with each other with electrostatic attraction. The smallest particles, which cannot exist separately connect into aggregates with the size to more than $20 \mu \mathrm{m}$.

The problem with aggregation might be overcome by using the surfactant powder as additive for milling. For this purpose, it is recommended to use PNS [26], [27]. Prevention of aggregation is achieved by adsorption of surfactant on the renewed cement grains.

There is one more reason for intergrinding cement with PNS: accelerate milling process (Fig. 3, curve 1). This can be explained by "Rehbinder Effect" - the reduction of hardness of material due to the formation of surfactant film on the material's surface [29]. The 
molecules of PNS are adsorbed on cement grains during the milling and hardness of grains is decreased. Therefore, for the same time duration the cement is intergrounded with PNS gains higher specific surface.

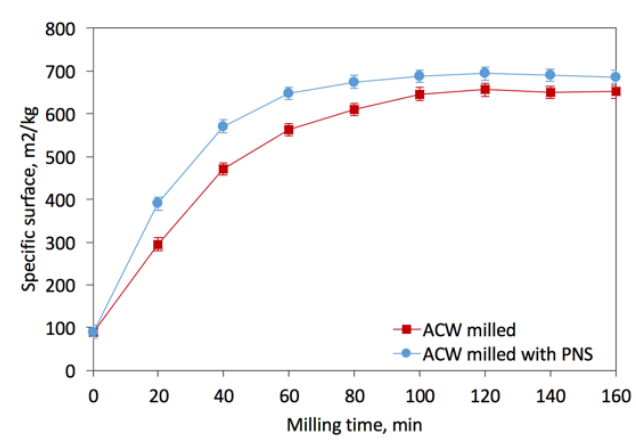

Fig. 3. Dependence of specific surface on milling time.

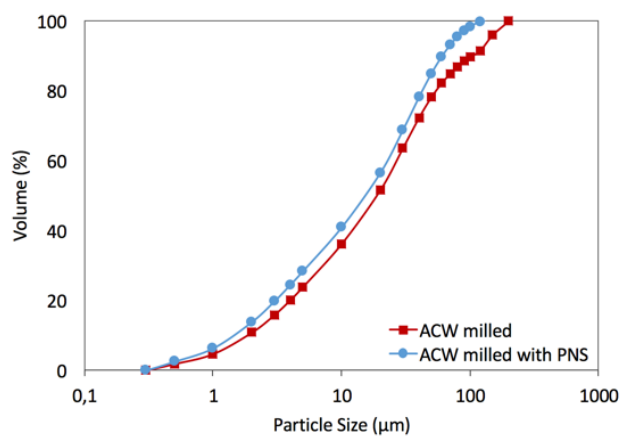

Fig. 4. Particle size distribution of milled ACW and ACW milled with PNS.

It also can be seen by particle size distribution analysis (Fig. 4). The milling with surfactant increases the amount of the small particles. On the one hand hydraulic activity is increased but on the other hand to keep the viscosity stable a higher water-to-cement ratio is required. The absorbed PNS particles on cement grains in cement paste act as a plasticizer and the viscosity remains unchanged.

The powder obtained by milling ACW was used for the preparation of the mortars. The different amounts of cement were substituted for this powder. The compositions and properties of the mortars are presented in Table 4.

Table 4. Properties of the mortars.

\begin{tabular}{|l|l|c|c|}
\hline$\#$ & Composition & Flexural strength, MPa & Compressive strength, MPa \\
\hline \multirow{2}{*}{2} & \multicolumn{3}{|c|}{ Reference } \\
\cline { 2 - 4 } & Reference & 5.1 & 39.6 \\
\hline \multirow{2}{*}{2} & \multicolumn{3}{|c|}{ Mortar is prepared with milled ACW, PNS is not introduced } \\
\cline { 2 - 4 } & 10 ACW & 4.4 & 30.8 \\
\hline \multirow{3}{*}{3} & \multicolumn{2}{|c|}{ Mortar is prepared with milled ACW, PNS is introduced with water } \\
\cline { 2 - 4 } & 10 ACW + PNS & 4.8 & 33.8 \\
\hline \multirow{4}{*}{4} & $10(\mathrm{ACW}+$ PNS) & 5.8 & 48.9 \\
\cline { 2 - 4 } & $15(\mathrm{ACW}+\mathrm{PNS})$ & 5.2 & 44.5 \\
\cline { 2 - 4 } & $20(\mathrm{ACW}+\mathrm{PNS})$ & 4.9 & 37.3 \\
\hline
\end{tabular}

The substitution of cement to $10 \%$ wt. milled ACW reduces the strength due to the higher specific surface and lower hydraulic activity of the ACW. The chemical introduction of PNS increases the strength but it is lower than the reference. Noticeable improvement is achieved by means of mechanochemical treatment. Intergrinding ACW with PNS significantly alters the strength properties. This phenomenon is ascribed to the more efficient applying of superplasticizer. During the mechanochemical treatment the PNS has been adsorbed on ACW particles more uniformly than with conventional chemical introduction of PNS (sample 3). Besides this mechanochemical treatment is allowed to reduce the particle size because of introduction of PNS into the mill. For the samples 3 and 4 the PNS amount is the same (ACW content is $10 \% \mathrm{wt}$.) but the strength is different. 
The results of the experiments present the influence of ACW content to properties of mortars. It is shown that mechanical properties increase with increasing amount of ACW. The best results are received from $10 \%$ to $15 \%$ wt. When the substitution of the cement reaches $20 \%$ wt. the mechanical properties decrease.

The influence of ACW content on kinetic of hardening was also investigated. For this purpose, two samples were prepared (Tab. 4) RF and 15 (ACW+PNS). In spite of the fact that specific surface of activated ACW is higher than ordinary cement, hardening development is slower (Fig. 5), because of the well-known retardation effect of PNS [30].

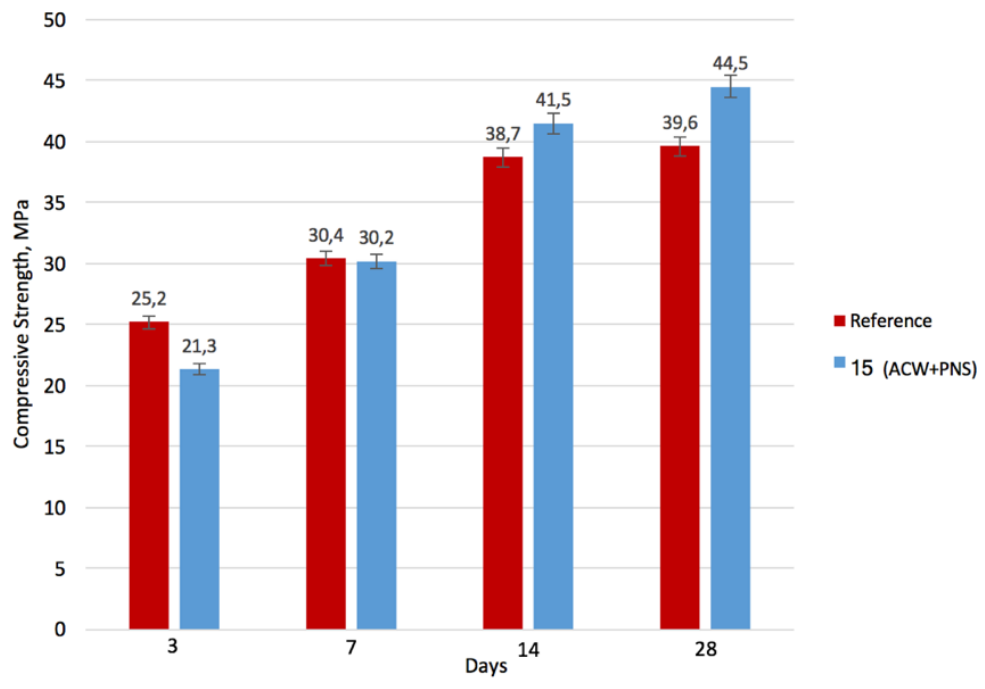

Fig. 5. Kinetics of hardening of mortars: $15(\mathrm{~A}+\mathrm{S})$ and reference.

\section{Conclusions}

The paper presents the results of ACW recycling using mechanochemical activation. It is shown that $\mathrm{ACW}$ comprises partly hydrated $\mathrm{C}_{3} \mathrm{~S}$ that can be reactivated by means of mechanochemical treatment in a vibratory ball mill. ACW is intergrinded with surfactant (PNS) affects the milling process: the specific surface of powder in presence of PNS grows faster than simply milling of ACW, that can be seen by particle size distribution analysis. Compressive strength of the mortars prepared with the product of treated ACW is increased by more than $20 \%$ with $10 \%$ wt. of cement replacement. The maximum substitution of cement to activated ACW is $15 \%$ wt. without loss of mechanical properties. The obtained results show that ACW could be successfully recycled as a replacement of the part of the cement in the blended binders.

The authors would like to thank for the support the Department of Building Materials of Moscow State University of Civil Engineering (Russia), Scientific Research Institute of Moscow Construction (Russia). Special thanks to scientific adviser for prof. Kirill N. Popov (1937 - 2013) and prof. Valery V. Kozlov (1937-2013).

\section{References}

1. Directive 1999/77/EC, vol. 6, 20718 (1999)

2. R. L. Virta, Worldwide asbestos supply and consumption trends from 1900 through 2003 (2006) 
3. R. L. Virta, Asbestos : Geology, Mineralogy, Mining and Uses, 1 (2002)

4. J. C. Wagner, Am. J. Public Health, 87, 4, 687-688 (1997)

5. M. Camus, CMAJ, 164, 4, 491-4 (2001)

6. C162 - Asbestos Convention, 162 (1986)

7. A. F. Gualtieri, Toxicity of Building Materials, 166-195 (Elsevier, 2012)

8. F. Colangelo, R. Cioffi, M. Lavorgna, L. Verdolotti, and L. De Stefano, J. Hazard. Mater., 195 391-397 (2011)

9. E. Gidarakos, K. Anastasiadou, E. Koumantakis, and S. Nikolaos, J. Hazard. Mater., 153, 3, 955-965 (2008)

10. A. F. Gualtieri and A. Tartaglia, J. Eur. Ceram. Soc., 20, 9, 1409-1418 (2000)

11. R. Kusiorowski, T. Zaremba, and J. Piotrowski, Ceram. Int., 40, 8 11995-12002 (2014)

12. A. F. Gualtieri, L. Veratti, A. Tucci, and L. Esposito, Constr. Build. Mater., 31, 47-51 (2012)

13. C. Leonelli., J. Hazard. Mater., 135, 1-3, 149-155 (2006)

14. K. Anastasiadou, D. Axiotis, and E. Gidarakos, J. Hazard. Mater. 179, 1-3, 926-932 (2010)

15. A. Viani and A. F. Gualtieri, Cem. Concr. Res., 58, 56-66 (2014)

16. A. Viani and A. F. Gualtieri, J. Hazard. Mater., 260, 813-818 (2013)

17. M. Gualtieri, A., Boccaletti, Constr. Build. Mater., 25, 8, 3561-3569 (2011)

18. Y.M. Bazhenov, L.I., Shubenkin, P. F., Dvorkin, Application of industrial wastes in the production of building materials (Moscow, 1986)

19. X. Guo, D. Xiang, G. Duan, and P. Mou, Waste Manag., 30, 1, 4-10 (2010)

20. V. V. Boldyrev and K. Tkáčová, J. Mater. Synth. Process., 8, 3/4, 121-132 (2000)

21. P. Plescia et al., Waste Manag., 23, 3, 209-218 (2003)

22. F. Trapasso, D. Croci, P. Plescia, and E. Tempesta, (3rd int conf Ind. haz waste, Crete, 2012)

23. S.M. Neiman, A., Bagautdinov, A., Bondarenko, Application of asbestos-containing waste into construction material production. Analytical review (Moscow, 1992)

24. G. Orentlikher, L., Soboleva, Constr. Mater., 7, 18-19 (2000)

25. L. Egorova, V. Semenov, A. Pligina, and A. Askhadullin, MATEC Web Conf., 86, 06005 (2016)

26. M. Bickbau, Nanotechnoligy in the cement production (Moscow, 2008)

27. V. R. Falikman, V.R., Bashlykov, Law water demand binder technology for environmental friendly cements with low clinker content, RILEM 633-642 (2011)

28. T. Feric, R. Krstulovic, J. Peric, and P. Krolo, Cem. Concr. Compos., 19, 4, 301-305 (1997)

29. P. A. Rehbinder and E. D. Shchukin, Prog. Surf. Sci., 3, 2, 97-188 (1972)

30. V. G. Batrakov, Modified concretes (Moscow, 1998) 